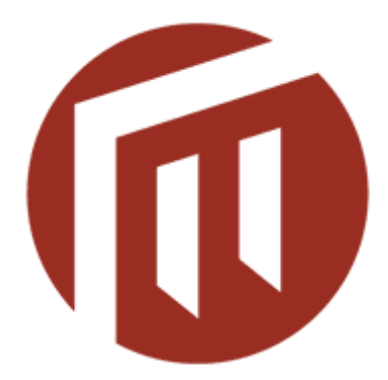

MALMÖ UNIVERSITY

\title{
Malmö
}

University Electronic Publishing

This is an author produced version of a paper published in Urban Forestry \& Urban Greening. This paper has been peer-reviewed but does not include the final publisher proofcorrections or journal pagination.

Citation for the published paper:

Ebba Lisberg J ensen, Pernilla Ouis

"Contested construction of nature for city fringe outdoor recreation in southern Sweden: The Arrie case" 2008, vol 4, issue 7: pp 171-182

URL: http:/ / dx.doi.org/ 10.1016/ j.ufug.2008.02.003

Access to the published version may require subscription.

Published with permission from: Elsevier 


\section{Contested construction of nature for city fringe outdoor recreation in southern Sweden: The Arrie case}

Ebba Lisberg Jensen, Ph.D.

Environmental Science, School of Technology and Science Malmö University 20506 Malmö SWEDEN ebba.lisberg.jensen@mah.se

Pernilla Ouis, Ph.D.

School of International Migration and Ethnic Relations Malmö University 20506 Malmö SWEDEN pernilla.ouis@mah.se \&

Human ecology division, Dept. of European Ethnology, Lund University Finngatan 16 22362 Lund SWEDEN 


\section{Introduction}

This study deals with the process of change from industrial to recreational land use on a 60 ha piece of land. The site called Lake Arrie is situated $12 \mathrm{~km}$ southeast of Malmö in southern Sweden (see Fig. 1). The lake, covering more than a third of the area, has originated from an abandoned gravel quarry in the midst of an agricultural landscape. It is argued that the case study of Arrie illustrates several general aspects of contemporary changes of land use in the contested city fringe. In this paper, we will put emphasis on conflicting interests, construction of nature and outdoor recreation, and on pluralism as a moral imperative. However, as the research project runs parallel in time with the planning and development process of the site, there is yet no final design of the area to be evaluated. The objective of this paper is to explore how complex social and political planning processes interact with changing and ephemeral views of nature and its physical manifestations in the landscape. Although the area itself is rather small and still in a transitional state, it provides significant examples of more general contemporary trends regarding landscaping in the city fringe. Results and knowledge produced in this research project are of a more general character, and are not primarily aiming at solving management issues in Arrie.

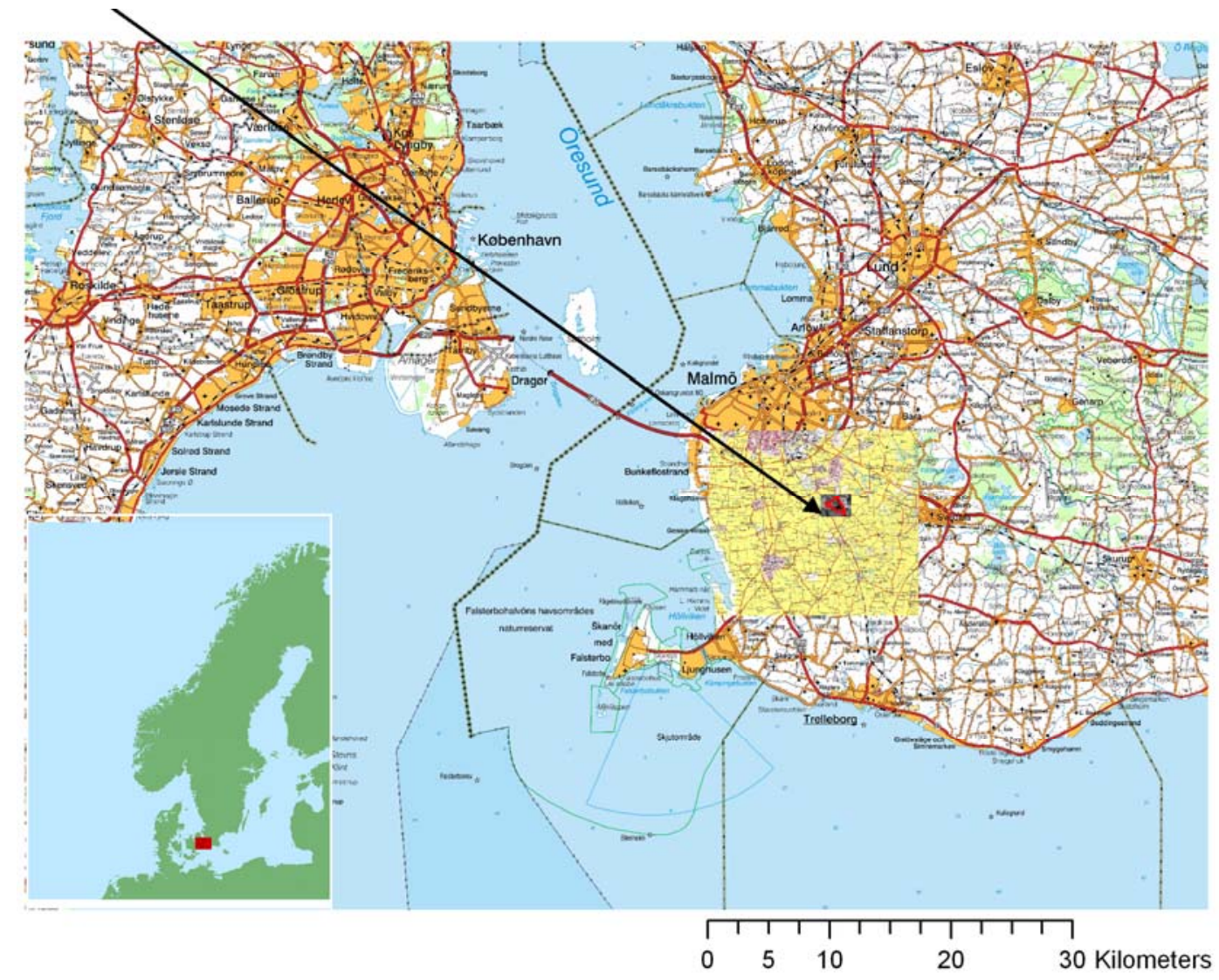

Fig. 1. The map shows the location of Lake Arrie in its' close vicinity to Malmö in Southern Sweden. (c) Lantmäteriverket Gävle 2008. Medgivande I 2008/0349 
Our study approaches the process from a human ecological point of view, looking at three 'levels of reality': the person, the society and the biophysical environment (Steiner, 1993, p. 56). None of those three take precedence over the other, but they are equally important to the multidisciplinary understanding of the process. Departing from this so-called 'human ecological triangle', we set out to identify and discuss the three levels, looking at the renegotiation of nature in the post-industrial society. The three levels can also be interpreted as constructions in three dimensions (Ouis, 2002): the mental, social and material dimensions. This differs from the social constructivist approach that tends to ignore the material reality (for a critique of such an approach, see Hacking (1999)). In this case, nature is constructed in the most physical of meanings: areas of wasteland are to be re-designed into nature for outdoor recreation. The new design, however, is ruled by contested ideals, social tensions and power relations, and those conflicts are in focus of our investigation.

In this paper, we present a short background to the area and the current situation in Lake Arrie, setting out to capture the tendencies of the contemporary construction of nature for outdoor recreation. We will then move on to discuss the salutogenic (health promoting) aspects of outdoor recreation, and how these can be understood in the landscape of Lake Arrie. We will further discuss the post-modern ideal of diversity as opposed to modernity's ideals of monoculture and universalism. Post-modernity cherishes diversity both in nature and culture. These ideals apply both to the planning process and to results in the landscape. To capture the multitude of voices emanating from different stakeholders, the process to extract local opinions through participatory processes is presented. Finally, we will discuss how contemporary views on post-productive nature tend to permeate the planning process as well as the cultural and physical construction of nature for outdoor recreation.

\section{Method}

The approach of this study is simultaneously multi- and transdisciplinary. The research group consists of researchers from the disciplines of environmental history, paleoecology, human geography, plant ecology and human ecology. The study includes empirical material from field inventories, historical sources, participant observations and interviews with key stakeholders and planners. A discourse analysis approach of planning documents will be utilised, in the sense that hidden meanings and power structures are of main concern, as are ideologies and values articulated in the expressions of the actors, in language and practice (Fairclough, 1992). 
Employing a trans-disciplinary approach, the present study aims at analysing how a former wasteland in the city fringe alters, both from an ecological and a cultural point of view. The fact that there is yet no implementation of the development program to evaluate poses interesting epistemological, methodological and ethical issues regarding the involvement of the researchers and our relationship to stakeholders. One central issue is on whether to interfere or get involved in decisions regarding the planning of the area. The dominating stance of the research team is to keep a distanced observers perspective, rather than taking an active part in the planning process. In spite of our participation in meetings and discussions, it is not an aim in itself to provide the planners with results, advice and opinions. Hence, the research team is in some sense involved, but we prefer - as far as possible - not to influence decisions before they are made. The County Council has not yet decided on the final management plan in January 2008.

\section{Case study description}

The piece of land in question has undergone substantial changes of use over the past century. Initially, it was used as grazing lands. Due to its poor soil condition it has not been suitable for cultivation. In the latter part of the $19^{\text {th }}$ century, a gravel quarry was opened. The gravel exploitation expanded and continued during the $20^{\text {th }}$ century, facilitated by a small railroad leading to the quarry. Close to the road in the northernmost part of the area, a limestone factory was established in 1907. The factory building of about 1000 square metres still remains. The lime needed for the industrial process was imported from Limhamn on the Baltic shore, south of Malmö. The industrial past has implications for the flora and fauna in the area today. Skabersjö, a nearby estate, and its industrial company (Skabersjö Industries Ltd.) owned the factory during the industrial era. Later on, the construction company PNB and the Swedish Road Administration owned and used the quarry until 1998.

The County Council of Scania (Region Skåne) purchased the larger part of the area of about 60 ha in 2004, in order to create a green space for outdoor recreation. The County Council is a politically ruled regional public body responsible for health, medical and dental services in Scania. Administration of recreational areas is included in this responsibility. Health aspects are closely connected to planning for outdoor recreation, as part of a plan to prevent obesity and diseases related to the late modern society and its lifestyles.

At the time of the purchase, the quarry had filled up with groundwater, creating one major pond (Lake Arrie in the local tongue) and several smaller ones (see Fig. 2). The species mentioned below may provide a picture on the diverse and ecologically transitional 
state of the area. When the planning is to be implemented, the ecology of the area will be changed according to recreational interests and preferences. Today, some species are remnants of the primary ecosystem, while others are very recent inhabitants in Arrie. For example, private anglers have probably ‘spontaneously’ established a stock of fresh water fish such as northern pike (Esox lucius L.), perch (Perca fluviatilis L.), roach (Rutilus rutilus L.), carp bream (Abramis brama L.), rudd (Scardinius erythrophthalmus L.) and European eel (Anguilla anguilla L.) in the lake. Birds nesting on the islands in the lake include red-necked grebe (Podiceps grisegena Bodd.), mute swan (Cygnus olor L.), coot (Fulica atra L.), tufted duck (Aythya fuligula L.), great crested grebe (Podiceps cristatus L.) and little ringed plover (Charadrius dubius Scop.). The smaller ponds in the surroundings provide habitats for rare or threatened species of amphibians and reptiles such as spadefoot toad (Pelobates fuscus Laur.), natterjack toad (Bufo calamita Laur.), edible frog (Rana esculenta L.) and sand lizard (Lacerta agilis L.). Some of these are sensitive to the rapid change of the vegetative cover. On the formerly intensely used gravel quarry, a greening succession soon started out, and today, the site is forming into a fallow, with silver birch (Betula pendula Roth), goat willow (Salix caprea L.), osier (Salix viminalis L.), silky-leaf osier (Salix x smithiana Willd.), elm (Ulmus glabra Huds.), aspen (Populus tremula L.), guelder-rose (Viburnum opulus L.) and Sherard's downy-rose (Rosa sherardii Davies) (Gyllin, 2007).

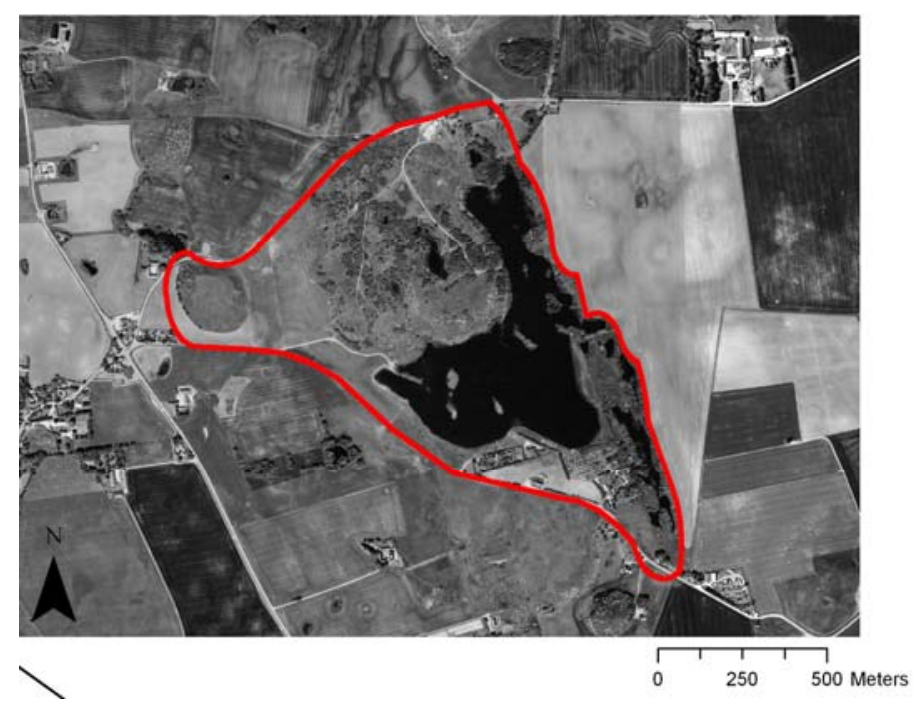

Fig. 2. Satellite picture over Lake Arrie. The dark water area was previously a sandy hill. The old lime-stone factory can be spotted as a white roof in the northern edge. The little round area to the left is one of the smallest nature reserves in Sweden, the Gavelsbjer. Toghether with the Arrie area, it forms an island of accessible green land in a densely populated and cultivated landscape. @ Lantmäteriverket Gävle 2008. Medgivande I 2008/0349 
Because of soil disturbance and excavation, ruderal plants have colonised the dry parts of the area, for example, hawthorn (Crataegus monogyna Jacq.), glaucous dog-rose (Rosa dumalis Bechst.), soft downy-rose (Rosa villosa L.), parsnip (Pastinaca sativa L.), cow-parsley (Anthriscus sylvestris (L.) Hoffm.), common nettle (Urtica dioica L.), common couch (Elytrigia repens (L.) Desv. ex Nevski), creeping thistle (Cirsium arvense (L.) Scop.), yarrow (Achillea millefolium L.), white dead-nettle (Lamium album L.), mugwort (Artemisia vulgaris L.), red bartsia (Odontites vulgaris Moench), wood small-reed (Calamagrostis epigeios (L.) Roth), greater knapweed (Centaurea scabiosa L.), dewberry (Rubus caesius L.), flattened meadow-grass (Poa compressa L.) and chicory (Cichorium intybus L.). As a consequence, insects dependent on those species have followed. Calcicole species, not found in the surrounding flora, have, as a result of lime import to the brick-works, established habitats such as small scabious (Scabiosa columbaria L.), basil thyme (Satureja acinos (L.) Scheele) and dwarf everlast (Helichrysum arenarium (L.) Moench). There are butterflies such as the moth Metzneria santolinella Ams. and six-belted clearwing (Bembecia ichneumoniformis Denis \& Schiff) (Gyllin, 2007).

\section{Users and stakeholders: A snapshot}

Three municipalities converge in Lake Arrie: Malmö, Svedala and Vellinge, of which the latter administrates the area (see Fig. 3). Those three municipalities differ a lot in socioeconomic structure. Malmö is Sweden's third city. It has an industrial tradition and currently has one of the country's largest proportions of immigrants. Svedala is a commuter and farmer community, with two villages and plenty of farmland. Vellinge is also a commuter and farmer municipality, but with an explicitly wealthy population. Vellinge is politically dominated by the right wing, while Malmö is a traditional social democrat-led municipality. Obviously, planners as well as users of the recreational area, have markedly different goals and ideals in their approach to the area. As a consequence, conflicts arise because of different perspectives among the different stakeholders. We will return to this below. 


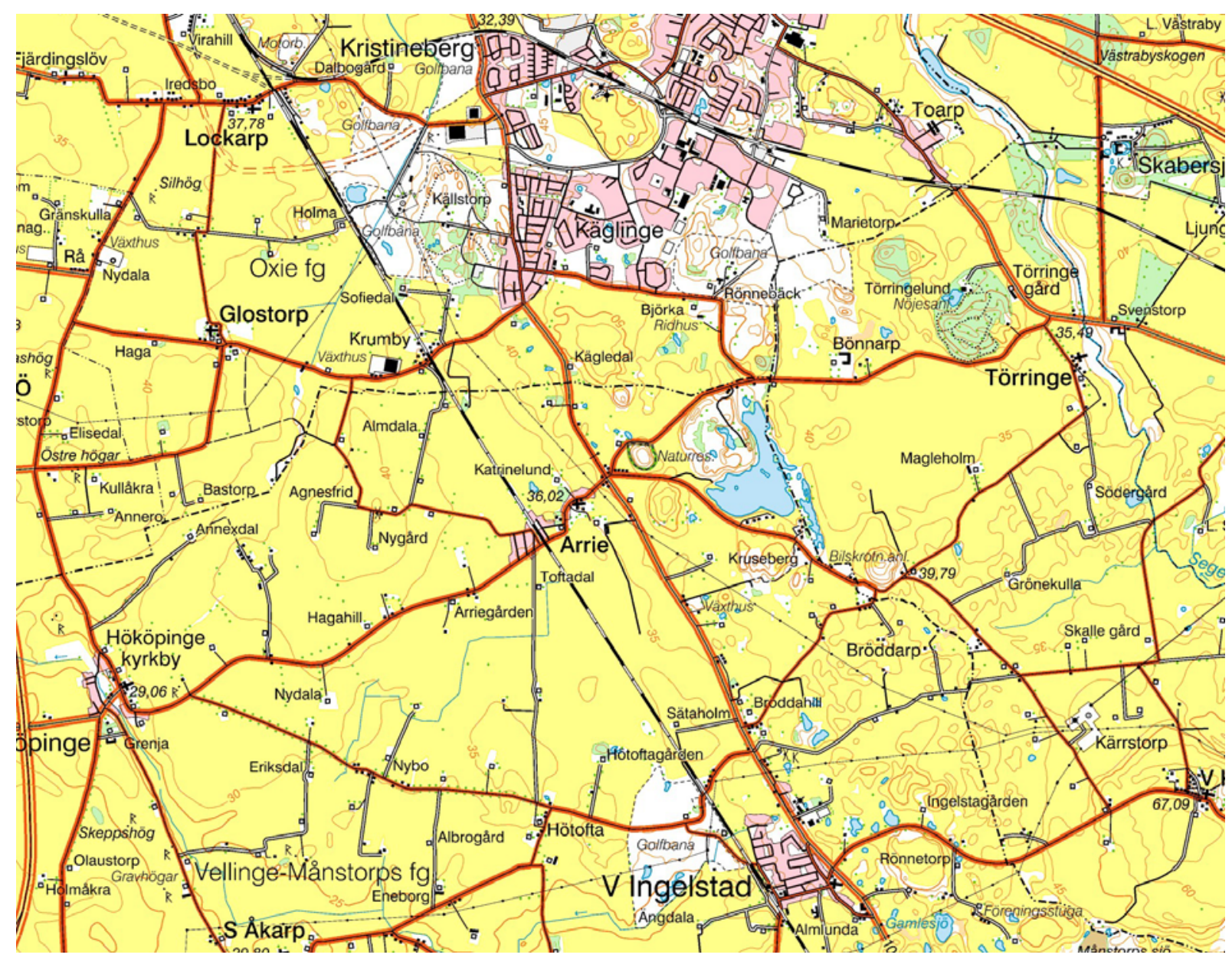

Fig. 3. Map over the actual area. C C Lantmäteriverket Gävle 2008. Medgivande I 2008/0349

The policy of the County Council is to encourage and facilitate access to the area for target groups of children, disabled and immigrants. The groups are targeted as their need for outdoor recreation is supposed to be enhanced. The County Council has also financially supported an association of immigrant parents from the closest suburb of Malmö to organise outdoor activities and projects in Arrie. A ‘suburb' in the Scandinavian context usually denotes a bigscale housing project, often inhabited by low-income groups and newly arrived immigrants, in the outskirts of the city. The County Council has as well formulated a combined set of objectives for their recreational areas: biodiversity, health and cultural integration (County Council of Scania, 2006). The objectives correspond to governmental political long-term goals for societal development in Sweden, under the overarching parole of sustainable development (for the national policy regarding outdoor recreation and health, see Statens folkhälseinstitut (2002)).

Today, the area provides a wide range of uses as an outdoor recreation facility. The majority of those uses are, this far, spontaneous or 'non-planned'. Since Lake Arrie is a small patch of land, where you almost have a view from one end to the other, the risk for user 
conflicts is obvious. Lake Arrie, situated in a densely populated region, does not provide total silence or wilderness experiences, however Swedish law and the landowners’ policy eliminates the most common disturbances, such as noisy motorised activities in recreational areas.

Anglers are among the most active users. A local anglers' club takes care not only of fishing arrangements, but has also volunteered to keep the shores clean of rubbish and to empty the dustbins along the road. A paint-ball-club is the tenant in the old factory building. The arrangements for paint-ball fights today occupy a meadow on one of the hills in the area. This club, though, is under notice, as the activity - seen as relating to violence - is not in line with the County Council's goals for use and management of recreation areas. Birdwatchers roam the area and a newly constructed bird-watching tower can be utilised on the shore of the lake. A cross-country runners' club arranges regular activities in the area. Although these activities do not formally exclude women, they mainly engage male users. According to our observations on the site, women in general seem to be more interested in activities such as walking, dog walking and horseback riding.

A private entrepreneur has established a company for outdoor events in the area. He manages a sauna raft that can be rented by parties of bathers in the lake. The entrepreneur has applied to expand his activities through building a so-called adventure trail. This raises the issue of possible conflicts between commercial and non-commercial uses. Another opposition can be identified between the needs to plan the area actively, and the spontaneous use, such as bathing and barbecuing at the little beach on the shore of the lake. A third conflict may occur between the local inhabitants that live in the villages close to the lake, who feel that the area is 'theirs'. There is a risk that locals perceive visitors from local suburbs as intruders. A cultural clash of this kind could be when groups of ethnic minorities go picnicking and barbecuing on the beach. There are also private landowners on the border of the designed recreational area, being important stakeholders. One major landowner is Skabersjö estate, controlling a strip of land on the eastern shore of the Lake Arrie. The County Council has been given permission to establish a trail on this land in order for visitors to be able to walk around the lake.

\section{Kraft durch Freude?}

Love for nature and outdoor recreation have since the late $19^{\text {th }}$ century been core factors in the construction of a national Swedish identity. During early Industrialism, nature came to symbolise an opposition to urban, productive and artificial environments. Romanticism and 
nostalgia seem to have been reactions to the up-rooting caused by urbanisation and industrialisation (Frykman and Löfgren, 1979). The Swedish Tourist Association and the Swedish Society for Nature Conservation helped to form the image of Swedish nature as a source for strong health and good morals from the early $20^{\text {th }}$ century and onwards. Basic knowledge of wild flowers, trees and animals became a central feature in the education of young Swedes.

In the late $19^{\text {th }}$ century, the declining health status of the working class in the deprived urban areas became an issue for the ruling class. This concern was not only from the social aspect but also from a moral point of view. Outdoor recreation was initially a bourgeois activity, but was promoted for 'lower' classes as a part of a social engineering project. Hygiene and exercise were thought to improve labourers' health. Tuberculosis and anaemia were illnesses to be cured by fresh air. In the cities, ornamental parks and promenades were created for the upper and middle-class people. At the same time, parks were created to provide workers with nature-like environments for recreation (Mels, 1999).

This approach was established at a larger scale by the Germans in the 1930s, also known by its motto Kraft durch Freude. This movement aimed at engaging workers in various edifying and recreational activities. The idea that outdoor recreation will enhance good behaviour and strengthen group dynamics is still alive. Even in recent times, outdoor recreation is often used in social work, to rehabilitate drug addicts and criminal youngsters (e.g., Andmarken 1979, pp. 99-102.) Later on, we will argue that the core idea to employ outdoor recreation for social purposes is still the same, but that the political ideologies and target groups have shifted dramatically.

The public health (salutogenic) aspects do no longer focus on bad lungs and low weight. Today public health work has turned towards the risks of obesity, lack of exercise and mental fatigue. The County Council of Scania refers to research showing clear connections between outdoor recreation, health and wellbeing:

"Regular stays in nature have a positive effect on both mental and physical health and decrease the time for rehabilitation after illness. There are large socio-economic gains for society in enabling people to visit nature to a larger extent and perform outdoor physical activities. The present economic monitoring system makes it difficult to show direct connections between investment for an outdoor recreation area and society's expenses for bad health. It requires a more long-term view by decision-makers than a few fiscal years to assert socio-economic gains of an outdoor recreation area" (County Council of Scania, chapter 3, p. 5, our translation). 
One interesting feature in the Arrie case is the implicit moral and political imperative that lies in outdoor recreation. Not only should visits to Arrie promote public health, it is also seen as a way for extra-Scandinavian immigrants to become more integrated into Swedish society. It seems obvious to us that the tradition of outdoor recreation as a social project with moral imperatives, expressed through the discourse of integration, is reflected in the policy of the County Council. Interestingly, it seems to be reproduced by the immigrant parents themselves as well, as a means to rise and educate their children in an activity encouraged by the establishment (field notes March 21, 2006). Immigrants may choose outdoor recreation as one strategy for acceptance in the Swedish society.

\section{Public health-related characteristics and landscape values in Arrie}

The political goals of the County Council are to plan for outdoor recreation in order to promote not only health aspects, but also biodiversity as well as cultural integration (County Council of Scania, 2006). In creating outdoor recreation areas such as Lake Arrie, all those three objectives are to be incorporated. But what kind of nature promotes health, and how can these benefits be combined with biodiversity and opportunities for integration?

At the Swedish University of Agricultural Sciences, recent research has set out to identify the capacity of green areas to promote health and well-being. Landscape architect Stigsdotter (2005) has developed a model on the eight basic characteristics of green garden rooms that make them popular, appreciated and visited. She bases the model on the works of Berggren-Bärring and Grahn (1995). The eight basic characteristics are the following (Stigsdotter, 2005, p. 17):

1. Serene. Peace, silence and care. Sounds of wind, water, birds and insects. No rubbish, no weeds, no disturbing people.

2. Wild. Fascination with wild nature. Plants seem self-sown. Lichen and mossgrown rocks, old paths.

3. Rich in species. A room offering a variety of species of animals and plants.

4. Space. A room offering a restful feeling of 'entering another world', a coherent whole, like a beech forest.

5. The Common. A green, open place providing vistas and inviting you to stay. 6. The Pleasure Garden. An enclosed, safe and secluded place, where you can relax and be yourself and also experiment and play.

7. Festive. A meeting place for festivity and pleasure

8. Culture. A historical place offering fascination with the course of time. 
In the suggested programme for development of Lake Arrie, the County Council relates to these eight characteristics, referring to them as 'recreation values' (County Council of Scania, 2006). Stigsdotter (2005) points out that the focus of the characteristics is to promote health in city green areas. Below, we will reflect upon the characteristics in relation to the situation in Arrie and to the draft of planning as it was presented in June 2006.

In the current situation, serenity seems to be experienced especially by locals (see Fig. 4). Serenity can easily be threatened if the occurrence of traffic, noise, crowding and littering increases. In the draft, it is emphasised that serenity should be protected as activities inevitably will increase in the area. Original wilderness, though, is absent, as the area is all a result of industrial process and intense use. The sense of wilderness might however be a real value to some people. The County Council suggests that it is possible to establish a forest feeling on the northwest bank. A high-forest, though, will not grow spontaneously, but will have to be planted and waited for. On the east shore of the lake a more wild nature is present as bushes grow uncontrolled close to the water sheltering birds and wildlife. As nature 'recolonises' this part of the area, it may be perceived as the most 'wild'. Paradoxically, this is the less visited part of Arrie. The 'natural' wilderness promoted by planners does not seem to be the most appreciated among visitors.

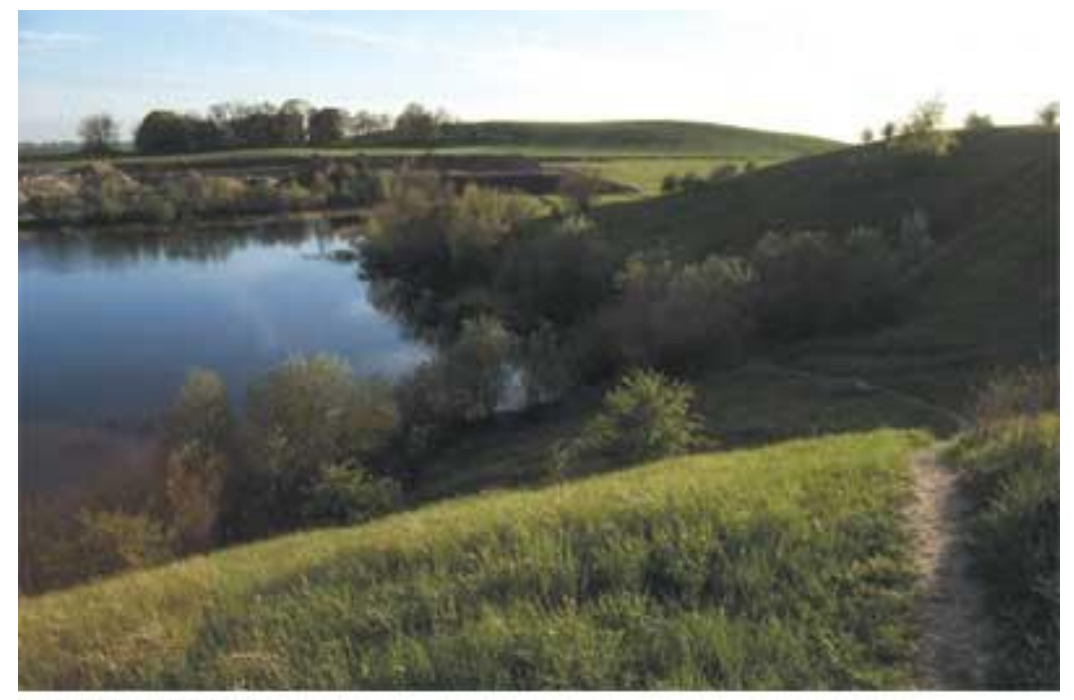

Foto: Per Blomberg

Fig. 4. View over the lake in springtime. By permission from the photographer.

Another major goal set up by the County Council is to increase local and regional biodiversity. This is an important aspect, as there are not many patches of biodiverse 'nature' in the mono-cultural agricultural landscape surrounding Arrie. The third characteristic, rich in species, is mirrored in Arrie especially due to the industrial past. The value, as such, does not 
have to reflect 'natural' biodiversity. But the idea to increase biodiversity through introduction of new species is still controversial. Which exotic species can be accepted, if a traditional park is not to be obtained?

The experience of space is naturally present because of the elevated position of the hills surrounding the lake. The major hill in the Lake Arrie area, Risebjär, provides the visitor with a grand view to the south. The view may be threatened if too much forest is introduced and if the under-growth is not held back. The question that should be posed is: Is it possible for such a small area to house senses of wilderness and space at the same time?

The common, the pleasure garden and the festive are all characteristics that can be experienced primarily on the northwest shores of the lake, as this area is accessible by car. This opportunity will be organised differently by the County Council in the future, as littering and disturbances may undermine the values preferred. Visitors with an immigrant background seem to appreciate these social aspects of outdoor recreation rather than biophysical characteristics such as wilderness, space and biodiversity.

The cultural aspect of a green area is not discussed in the draft at all. One possibility would be to emphasise the socio-economic history of the area, for instance by providing information on the quarry and the limestone factory. It is quite significant that the County Council has neglected the interesting cultural and historical aspects of the factory ground. Nature for recreation - i.e. nature seen as devoid of humans and their activities - is in focus rather than culture. To go outside the city may however also be a way to go 'back in time'. Recreation may thus be considered an escape in both time and space (see Svensson, 2000).

\section{The imposed diversity}

A central feature of the modern society has been the belief in universalism and uniformity, implemented in politics both in social engineering and in management of nature. As a reaction to the problematique associated to these values, alternative movements during the 1960s and 1970s argued for the values inherent in diversity and pluralism. In the late 1980s, environmentalists introduced the concept of biodiversity as a value to be protected in nature (Lisberg Jensen, 2002). This value was presented as a prerequisite for both balance and dynamics in nature. At the UNCED conference in Rio 1992, the concept was internationally articulated in the Convention of Biological Diversity. The idea of biodiversity can be interpreted as a reaction to modern agriculture and forestry, promoting increased preservation. The idea can also, and less explicitly, be seen to represent an essential value of nature, that is, 
the 'untouched', 'natural' state of things. Because monoculture dominates the agricultural surroundings, species diversity is to be appraised and encouraged in Lake Arrie.

Diversity has also become a buzzword in social planning, opening societal acceptance for a wide variety of ethnic origins. Swedish immigration politics in the 1960s were rather strict in terms of their assimilation policy, i.e., immigrants were demanded to give up their original cultural identity in order to become Swedish (Johansson, 2005). In contemporary politics, ideals have changed towards an integration based on diversity. Diversity, it seems, both among species and humans, has become an often cited, but somehow unspecific parole, denoting 'all things good'. The County Council of Scania, as a political body, reproduces this approach. In Lake Arrie, not only biodiversity should be promoted, but also values of cultural diversity:

"There is a big potential in the area for increased understanding and integration. Through outdoor recreation [...] and different types of cultural activities, citizens with different cultural and ethnic background and preconditions get to know and appreciate one another” (County Council of Scania, 2006, chapter 3, p. 4, our translation).

Politically correct, as this may be, there is a naive belief that cultural and biological diversity automatically and peacefully will appear.

The idea of diversity raises questions regarding essentialism contra constructivism. Cultural identities are always considered volatile, constructed and in process of change. For example, 'Swedishness' and integration is thought to be achieved through outdoor recreation. The notion that ethnicity is an essential quality is considered racist in contemporary discourse.

However, in nature conservation policy, framing the development of Lake Arrie, the opposite holds true. Species are seen as essential, not constructed, but also ecosystems and nature itself are more or less thought of as 'natural'. In Lake Arrie, the problem is rather to define 'original' nature. We will return to this below.

\section{Public fora: A participatory process}

In contemporary planning and management, authorities try to promote public participation through techniques of elicitation (Lezaun and Soneryd, 2006). A technique that is often employed to capture the opinion of the 'silent majority' is samrådsmöten, public fora. This is to ensure local support for political decisions, and to avoid top-down-planning that may cause 
mistrust and conflict. In order to do this, the choice of stakeholders - to 'extract' local opinion - is of great importance. Obviously, the agenda and organisation of such gatherings are of importance to how the process proceeds. There is always a delicate balance between chaos of voices and an overtly strict or limited possibility to speak up. While spontaneous expressions are and should be welcomed in the process, headstrong stakeholders may cause too much uproar for the process to continue. Therefore a focus on the opinions of the silent majority is preferred and promoted, rather than those of activists, educated upper middle-class or stakeholders promoting interests too private to count in the public planning (see Lezaun and Soneryd, 2005).

The stakeholders and current users presented above have all been invited to take part in the participation process in Lake Arrie. Presently, the County Council is in the middle of the consultation process, and the development program for Arrie is still to be decided upon by regional politicians. On the first public forum on Arrie, $21^{\text {st }}$ of March 2005, 80 stakeholders met to discuss the establishment of the recreation area. Some groups of stakeholders were given the opportunity to present their activities and ideas from the stage. Representatives of regional politicians and officials from the County Council and the municipalities presented thoughts and ideas about the future of the area. The following goals were explicitly emphasised by the officials (field notes):

- “To reach school children”

- "To increase access for disabled"

- "To give immigrants without that background", "with no habit of the right of public access”, “a possibility to roam the Scanian nature”, (a nature characterised as) "free from wild animals"

- “To increase biological and social values”

- "To increase information”

- “To decrease the risk of conflicts”

Among the public, a number of groups took the opportunity to present their ideas. A private entrepreneur was the first to present his ideas about the adventure trail. He also expressed a wish to rent a part of the factory building for setting up a restaurant and a climbing wall. A representative from the anglers' club told of their management of the lake and their efforts to keep the area free of litter. A group of cross-country runners wished to map the area thoroughly, and emphasised the need not to 'wear it out'. A parental organisation from the nearby suburb, was represented by a Swedish consultant, flanked by 
one mother of Arab origin and another of Somali origin. They presented a variety of plans for the area. Primarily, the factory building attracted the organisation, functioning as a facility for cross-cultural encounters, café and restaurant, a kindergarten, a multicultural workshop and activities for suburban youth. The immigrant ladies pointed out that "nature and environment are pathways into the Swedish society”. One of the few concrete ideas presented by the consultant was to arrange a 'zoological safari' in Arrie. Another idea was to use the area as an educational ground to inform and introduce immigrants about the Swedish Right of Common Access (allemansrätten). Despite what could be feared due to the number of divergent aspirations at the gathering, no xenophobic stances were expressed during the meeting. The public emphasises however that visitors must be provided with the 'proper knowledge' on how to behave in nature.

One decision that was proclaimed beyond discussion was the building of a birdwatching tower on the western shore of the lake. This, namely, had to be constructed before the $1^{\text {st }}$ of July, because of the funding already given by the European Union in the context of Nortrail (a network linking footpaths and sites in recreational areas of the coastal counties encompassing the North Sea). It can be interpreted as if decisions taken on a super-national level are not to be negotiated in local participatory processes. Another interpretation is that external resources, in scarce situations, tend to exclude local debate.

The open discussion that followed included detailed issues regarding, for example, the paint-ball club, beach and swimming facilities, the access for horses and dogs, traffic, service and street lights. In addition, some locals expressed an anxiety that the tranquillity would be threatened due to development of the area. "I have grown up here and chose to live here, and this has to do with the peace and quiet - what will happen in the future? Not that we do not want to share, but one might feel worried...” one woman said, and others hummed in consent. The County Council representatives answered that silence is a very important quality in recreation areas, and reassured that order will improve under their future management, instead of the previous 'Wild West' circumstances (field notes). An official from the neighbouring municipality added that parts of the surroundings will be exploited for housing, and that locals might have to get used to the idea of more people visiting the area. City sprawl will inevitably have impact on the use and categorisation of the area.

The public meeting revealed no dramatic controversies. Nevertheless, some latent conflicts can be spotted, like in many outdoor recreation areas. One of the most common, according to Jacob and Schreyer (1980), on their model on outdoor conflict, is on 
type of activity and the meaning assigned to it. Conflicting interests and differing activities, as well as the meaning given to those, are obvious in Lake Arrie. Another factor recognised in the model is sense of possession, connected resource specificity, where intimate knowledge of the area is crucial. Local identity and embeddedness are crucial for users' emotional attachment to Lake Arrie. However, this attachment can be attained by anybody through time, but there is no doubt that the local population connects more directly to the area (see Borgström Hansson, 2003). A third factor is the expectations on the experience of the environment. Such expectations can be divided into the list of characteristics previously discussed. The final factor, that may also be contested, is on tolerance towards other lifestyles and activities (Jacob and Schreyer, 1980). In Lake Arrie, there are potential conflicts of this kind, though not so harsh, related to local and/or ethnocentric perspectives towards outsiders (Rojek, 2005). Conflicts may occur openly if pressure on the facilities as well as expectations on experience increases.

\section{Conflicting ideologies}

Lake Arrie has been purchased to serve all county citizens, creating opportunities for outdoor recreation. This, of course, can cause conflicts between groups of users. The Right of Common Access allows everybody in Sweden to roam lands that are not cultivated fields or private housing grounds. The locals, living close to the quarry, have since long used the area as a common, using it for dog walking, fishing and horse-back riding. They have expressed anxiety about competition from outsiders visiting the area, and might not approve of the policy of increased access for the public and the explicit efforts to encourage immigrants to use the area. On the other hand, immigrants of various origins are not easily incorporated in the very culture-specific style of outdoor recreation of Scandinavia. Traditionally, this style has focused on values such as silence, solitude, hardiness and an amateur scientific interest in flora and fauna. These ideals may not apply to all Swedes and may be contested today. In many non-Scandinavian cultures, such as in the Middle-East (Ouis, 2002), visits into the wilderness alone and without practical reason are considered as strange behaviour. In Blomqvist's study on immigrants' outdoor recreation in urban settings, non-Scandinavian informants expressed an unease to roam alone in nature (Blomqvist, 2003). Instead, going out to picnic on a nice setting is primarily a social activity to these users. In this context, nature provides the visitor with pleasant scenery for social gatherings, rather than a being a source of challenge and self-improvement. The current attempts to reach integration through outdoor recreation, motivated by the health perspective, tend to reproduce the Scandinavian model for 
outdoor recreation. From now on, it is obvious that outdoor habits other than the Scandinavian have to be taken into consideration in planning for a range of users from different cultures and nationalities.

Planning has to reflect the current ideologies and aesthetics regarding the environment, as well as the potential of the area in question. A virginity of nature, traditionally cherished by early outdoor recreationists, cannot be found at all in Lake Arrie. Emmelin (1997) has coined the term 'purist' to denote those that prefer nature untouched by human hand for recreational purposes. In contrast, a stance that accepts or even prefers human intervention in outdoor recreation, such as prepared trails, bridges, information signs and facilities, is called 'urbanist' (ibid.). In Lake Arrie, the plan is to adapt the area to a wide range of target groups, as previously mentioned. The ideology of the County Council must be seen as 'urbanist' in terms of planning for access, while maintaining or enhancing the feeling of 'natural' nature. This raises the question: To what extent can nature be developed or altered in order to meet the needs of humans without losing its recreative qualities?

One of the most common land use-conflicts is the one between production and preservation, for instance when it comes to protecting biodiversity in old growth forests. This conflict is a non-issue in this case. There is no interest in preserving Lake Arrie in the state it is today. However, there is no interest either in any production in the area, as it is a 'left-over' from the industrial era. It has never been suitable as arable land, and certainly not for modern farming techniques. However, the patch of land will be used for another kind of production, but rather a production of experience and recreation in the field of consumption. In other words, this can be seen as the transition from a landscape of production to a landscape of consumption, or a change from concrete production to abstract production. This is a fundamental aspect of the post-industrial construction of nature.

All these conflicts seem to exemplify the four factors in the model of conflict mentioned above (Jacob and Schreyer, 1980). But users of an outdoor recreation area cannot easily be defined in terms of culture and habits. Even gender aspects matter, since men and women tend to differ in their outdoor practices and needs. Women, for instance, do emphasise the need to feel secure and not to be offended or approached by strangers. American outdoor research has shown, for example, that women of a variety of cultural origin use a number of strategies to avoid the sense of intrusion of their outdoor recreation experience (Wesely and Gaarder, 2004). This should also be taken into account when planning for recreation. But there is also fear and mistrust between other groups of users, between immigrants and Swedes, as well as between immigrant groups of different ethnic origin. One such example 
came to the fore during a meeting with the planning group of Arrie, when an official from Vellinge expressed the risk for citizens in their municipality to feel scared if they "have to meet veiled Muslim women in the forest” (field notes). The city fringe is an area of encounters, not only between the urban and the rural, but also between urbanists and purists, classes, ethnic groups and men and women.

\section{Constructing natural nature for outdoor recreation}

Above, we have shown that though nature in Lake Arrie is of a diverse origin and type, there is no original, untouched ecosystem to be restored. Nevertheless, the species and ecosystem present are an unplanned consequence of the anthropogenic and historical past of the area. We have raised the question to which extent nature can be designed and constructed without losing the sense of essential nature, unlike an urban park. It is a tradition in growing cities to plan for green areas for the well being of citizens on former wastelands such as dumps (Qviström, 2005). This tradition is not entirely new or Swedish. Even the most 'wild' landscapes are often constructed and designed. Green spaces for outdoor recreation have since the late $19^{\text {th }}$ century been designed and constructed in connection to big American cities, and are today considered remainders of wilderness in the urban landscape (Whiston Spirne, 1995, p. 104). This is however an illusion, due to skilful planning and design by human hand (ibid, p. 112) - a deliberate reconstruction of landscape.

As an example, to illustrate the possibility of designing nature, students of landscape architecture have in an adjacent project suggested the introduction of several exotic species in Lake Arrie. To increase the interests and recognition of immigrants in Lake Arrie, it has been suggested to plant orchard trees of foreign provenience, such as cedar, mulberry and walnut trees. Essential or original nature is long by gone in this case, but how far can we accept constructivism in physical reality? This is an established practice in urban parks, but is rather a new and controversial idea in nature outside cities.

From a human ecological point of view, society, human ideas and nature are all to be seen as actors in the process of creating and recreating nature. In the case of Lake Arrie, the present ecosystem has appeared without planning and management. From this perspective, nature is an agent in the process, and the County Council cannot by-pass the biological or historical agency in the area. Human intervention in nature is not a new phenomenon, but in the case of Lake Arrie, the County Council still seems uncertain whether to radically alter the biophysical state of the area or just to let the ecological processes proceed. Some years have already passed since the time of purchase, without decisions being made and without any 
management so far. This time span allows the ecological succession to continue. This may be a sign of the postmodern condition, where a multilayered history and diversity in goals of users are expressed and should be taken into account. This often results in a state of uncertainty and indecisiveness.

\section{Conclusion}

The social and political categorisation of an area reflects the needs of a changing society (see Fig. 5). In the case of Lake Arrie, we can identify several phases of transition between rural, urban, productive and recreational landscapes, both in terms of actual use, but also in terms of categorisation. In the early industrial era, the area was an enclave of industrial ground in a completely rural setting. In the post-industrial era, it turned into a 'wasteland', open for nature to recolonise. This type of landscape is difficult to categorise, being a space 'in between', neither nature nor culture, perceived as ephemeral and inferior. At the same time, the city sprawl has come closer, with the semi-urban populations' need for outdoor recreation. In the future, the former industrial ground will be perceived as an enclave of nature in an urban setting. When the former products of the area responded to the industrial need for gravel and limestone, the contemporary 'products' respond to emotional needs. The investments made are rather of moral, aesthetic and political character. Isn't it ironic, that what is most needed in a totally urbanised and modernised landscape is a room where people can perform activities like fishing, swimming and socialising in 'nature'? Constructed, culture-specific and planned as those activities may be, they also form an organised escape in time and space from a society that is organised to provide health, safety and happiness for everybody.

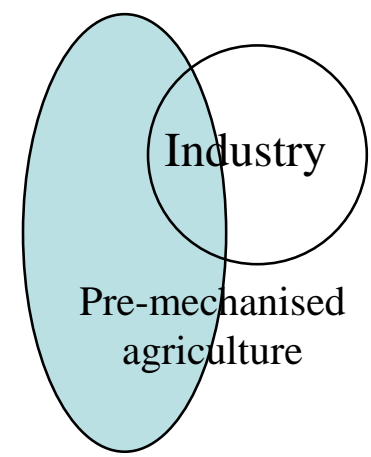

Past: Arrie as an industrial enclave in a pre-mechanised agricultural setting in early 20th century

Present:
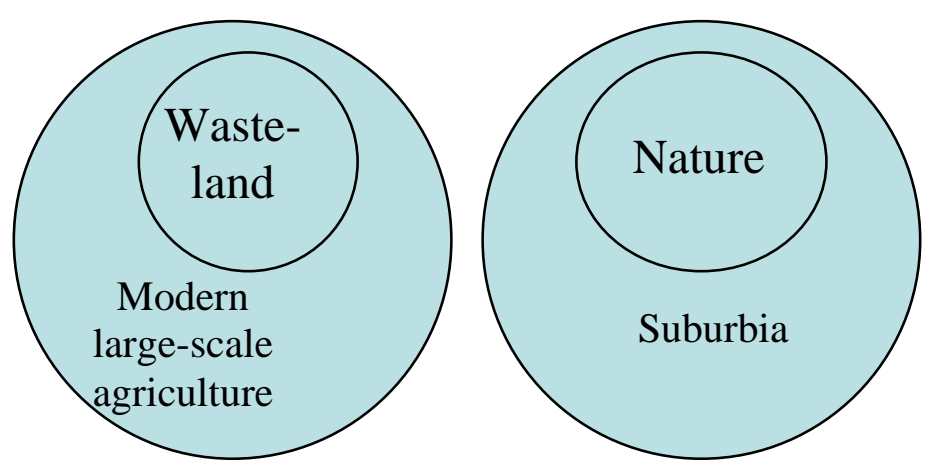

Future:

Arrie as a post-industrial wasteland in traftere:

Fig. 5. The perception, categorization and design of Arrie in relation to surroundings 


\section{Acknowledgements}

We take the opportunity to express our gratitude towards Sparbanksstiftelsen Skåne, whose generous grant has made this research possible. We also want to thank our project colleagues Anna Broström, Per Eliasson, Per Hillbur and Mats Gyllin for assistance and constructive comments, and Patrick K. Deans and James Potter for extra English-eyed readings. 


\section{References}

Andmarken, L., 1979. Friluftsliv för ungdom i riskzon (Outdoor recreation for youngsters on border of criminal behaviour). In: Bergström, A., Bragderyd, T., Fogelberg, T., Gustafsson, K. \& Hansson, C. En bok om friluftsliv. Liber förlag, Malmö, pp. 99-102. (in Swedish).

Berggren-Bärring, A-M., Grahn, P., 1995. Grönstrukturens betydelse för användningen: En jämförande studie av hur människor i barnstugor, skolor, föreningar, vårdinstitutioner mfl., organisationer utnyttjar tre städers parkutbud (The meaning of green structures for usage: A comparative study of how people in kindergartens, schools, NGOs, care institutions etc. use the parks of three cities). Landskapsplanering, rapport 95:3. Swedish University of Agricultural Sciences, Alnarp (in Swedish).

Blomqvist, L., 2003. Invandrare i tätortsnära natur: Kvalitativa intervjuer angående natursyn och nyttjande samt förslag till åtgärder (Immigrants in nature close to urban settings: Qualitative interviews concerning views and utilisation and proposed measures to increase usage). Graduation project no 22. Swedish University of Agricultural Sciences, Uppsala.

Borgström Hansson, C., 2003. Misplaced concreteness and concrete places: Critical analysis of divergent discourses on sustainability. Lund Studies in Human Ecology, Lund.

County Council of Scania (Region Skåne), 2006. Arriesjöns strövområdeutvecklingsprogram. Utkast 2006-06-02 (Recreational area of Lake Arrie development programme. Draft). Helsingborg (in Swedish)

Emmelin, L., 1997. Turism, friluftsliv, naturvård: Ett triangeldrama (Tourism, outdoor recreation and conservation: an eternal-triangle drama). Mitthögskolan, Östersund (in Swedish).

Fairclough, N., 1992. Discourse and social change. Polity Press, Cambridge.

Frykman, J., Löfgren, O., 1979. Den kultiverade människan (Cultivated man). Liber, Malmö (in Swedish).

Gyllin, M., 2008. Inventory of species in Arrie. Under publication, in Malmö University Publications in Urban Studies no 3.

Hacking, I., 1999. The social construction of What? Harvard University Press, Cambridge and London.

Jacob, G., Schreyer R., 1980. Conflict in outdoor recreation: A theoretical perspective. Journal of Leisure Research 12, 368-80.

Johansson, C., 2005. Välkomna till Sverige? Svenska migrationspolitiska diskurser under 1900-talets andra hälft (Welcome to Sweden? Swedish migration policy discourses during the second half of the $20^{\text {th }}$ century). Bokbox, Malmö (in Swedish).

Lezaun, J., Soneryd, L., 2006. Government by elicitation: Engaging stakeholders or listening to the idiots? Discussant paper. Carr, London School of Economics, London.

Lisberg Jensen, E., 2002. Som man ropar i skogen: Modernitet makt och mångfald i kampen om Njakafjäll och i den svenska skogsbruksdebatten 1970-2000 (As the question so the answer: Modernity, power and diversity in the struggle over Njaka-fjeld and in Swedish forestry debate 1970-2000). Lund Studies in Human Ecology, Lund (in Swedish).

Mels, T., 1999. Wild landscapes: the cultural nature of Swedish national parks. Meddelanden från Lunds universitets geografiska institution, Lund. 
Ouis, P., 2002. Power, person and place: Tradition, modernity and environment in the United Arab Emirates. Lund Studies in Human Ecology, Lund.

Qviström, M., 2005. In the shadow of the city: on landscape transformations and spatial planning at the inner urban fringe. In: Landscape change, Conference proceedings (ECLAS 2005). Ankara University, Department of Landscape Architecture, Ankara, pp. 241-250.

Rojek, C., 2005. Leisure theory: Principles and practices. Palgrave/MacMillan, New York.

Statens folkhälsoinstitut, 2002. Prop. 2002/03:35. Mål för folkhälsan: Handlingsplan för goda matvanor och ökad fysisk aktivitet i befolkningen (Goals for public health: Action plan for good food habits and increased physical activity in the population). Stockholm (in Swedish).

Steiner, D., 1993. Human ecology as transdisciplinary science, and science as part of human ecology. In: Steiner, D., Nauser, M. (Eds.), Human ecology: Fragments of antifragmentary views of the world. Routledge, London \& New York, pp. 47-76.

Stigsdotter, U.A., 2005. Landscape Architecture and health: Evidence-based health promoting design and planning. Swedish University of Agricultural Sciences, Alnarp.

Svensson, B., 2000. The power of cultural heritage tourism: Relations between culture and nature in historical landscapes. In: Hornborg, A., Pálsson, G. (Eds.), Negotiating Nature: Culture, Power and Environmental Argument. Lund University Press, Lund, pp 37-59.

Wesely, J.K., Gaarder, E., 2004. The gendered 'nature' of the urban outdoors: Women negotiating fear of violence. Gender and Society 18(5), 645-663.

Whiston Spirne, A., 1995. Constructing nature: The legacy of Frederick Law Olmsted. In: Cronon, W. (Ed.), Uncommon ground: Toward reinventing nature. W.W Norton and Company, New York and London, pp. 91-113. 